\title{
Spectrophotometric determination of niclosamide Via Schiff's base formulations in pharmaceutical and veterinary preparations
}

Determinación por espectrofotometría de la niclosamida a través de formulaciones base de Schiff en preparaciones farmacéuticas y veterinarias
Author:

Othman N S

Saleem I $\mathbf{T}^{2}$

\section{SCIENTIFIC RESEARCH}

How to cite this paper:

How to cite this paper: Othman N S, Saleem I T, Spectrophotometric determination of niclosamide via Schiff's base formulations in pharmaceutical and veterinary preparations. Innovaciencia. 2019; 7 (1) : 1-9.

http://dx.doi.org/10.15649/2346075X.512

Reception date:

Received: 10 May 2019

Accepted: 2 September 2019

Published: 25 October 2019

Keywords:

Niclosamidem, para-N,N- dimethylanimobenzaldehyde ;Schiff'sbase ;Spectrophotometry

\begin{abstract}
Introduction: Niclosamide(NICS) its chemical name 5-chloro-N-(2chloro-4-nitrophenyl)-2-hydroxybenz-amide] is the only commercially existing molluscicide optional by the WHO for large extent use in schistosomiasis be in charge of programs . NICS and its two new synthesized derivatives constructed to float on the water surface were able to kill cercariae, also obsessed promising activity in vitro nearby to an apicomplexan parasite Toxoplasma (4). Few spectrophotometric methods have been reported for the estimation of NICS as pure and in formulations, approximately these methods depend on reduction of nitro group (almost with zinc powder in acidic medium) followed by reaction with different reagents. The method based on reduction of nitro group of NICS then reaction of reduced-NICS with para- N,N-dimethylaminobenzaldehyde in non-aqueous medium (methanol) to form a colored product that has been proved successfully for the estimation of NICS in pharmaceutical and veterinary formulations Material and method :All reagents used are of analytical grade and are obtained from Fluka or Aldrich, NICS was supplied from SIGMA companies. Methanolic solution of para- N,N- dimethylanimobenzaldehyde (Fluka) 3\%, weighing $3 \mathrm{~g}$ and dissolved in 100 $\mathrm{ml}$ methanol in a volumetric flask. All other reagents were prepared by dissolving the propriety weight in perfect solvent. A volume in the range of 0.1 to $1.7 \mathrm{ml}$ of $100 \mu \mathrm{g}$.ml-1RNICS solution was transferred to $10 \mathrm{ml}$ calibrated flasks.2ml of PNNDMABA (3.0\%) was added, and the volume was made up to $10 \mathrm{ml}$ by adding methanol. The yellow Schiff's base was measured at $454 \mathrm{~nm}$ versus a blank solution. Results and Discussion:The optimum $\mathrm{pH}$ for reaction of NICS with para-N, N- dimethylanimobenzaldehyde equal to 3 which resulted by mixing the components of the reaction. The absorbance increase with increasing reagent concentration (para-N,N- dimethylanimobenzaldehyde) and reached maximum on adding volume of $2.0 \mathrm{ml}$ of $(3 \%)$, which also gives the highest value of determination coefficient (R2). The experimental data indicated that methanol was the optimum solvent used in dilution according to high intensity of Schiff's base and the good stability. The formation of the yellow Schiff's base being complete after mixing the components of reaction and the absorbance remained constant for at least 2 hours. Conclusion: Accurate and sensitive spectrophotometric method was described for the estimation of NICS. The present method has been successfully applied for the estimation of NICS in pharmaceutical and veterinary preparations.
\end{abstract}

\footnotetext{
1 Department of Chemistry, College of Science, Mosul University, Mosul, Iraq, nsn20002004@yahoo.com

2 Department of Chemistry, College of Science, Mosul University, Mosul, Iraq .
} 


\section{INTRODUCTION}

Niclosamide, its chemical name 5-chloro-N(2-chloro-4-nitrophenyl)-2-hydroxybenz-amide(Scheme I)] is the only commercially existing molluscicide optional by the WHO for large extent use in schistosomiasis be in charge of programs (1)



\section{Scheme I: Chemical structure of niclosamide}

NICS and its two new synthesized derivatives were constructed to float on the water surface were able to kill cercariae $\stackrel{(2,3)}{ }$, also obsessed promising activity in vitro nearby to an apicomplexan parasite Toxoplasma ${ }^{(4)}$. Few spectrophotometric methods have been reported for the estimation of NICS as pure and in formulations, approximately these methods depend on reduction of nitro group(almost with zinc powder in acidic medium) followed by reaction with different reagents such as metol and $\mathrm{K} 2 \mathrm{Cr} 2 \mathrm{O} 7$ in acidic medium ( $\mathrm{pH} 3.0)$ to produce a red color, it

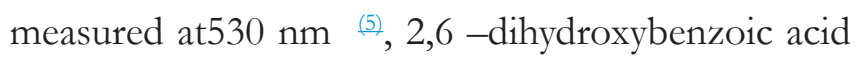
after diazotization to form yellow azo dye having maximum absorbance at $456 \mathrm{~nm}{ }^{(6)}, 1,10$-phenanthroline to give red complex, its maximum absorbance at $510 \mathrm{~nm}$ (7) and p- benzoquinone to form a pink product which absorbs at $506 \mathrm{~nm}{ }^{(8)}$. The derivative spectrophotometric methods have also been used in simultaneous determination of NICS in presence of author drug such as: drotaverine hydrochloride, (9) thiabenazole $\stackrel{(10)}{2}$ in the same formulations.NICS in tablets has been estimated by dissolving the tablets in $0.1 \mathrm{M} \mathrm{NaOH}$ solution, then measuring the

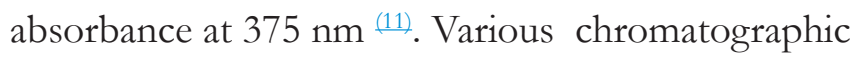
methods include high performance liquid chroma- tography $\stackrel{(12-15)}{ }$, LC-MS-MS $\stackrel{(16,17)}{\text { gas chromatogra- }}$ phy. ${ }^{(18)}$. The electrochemical methods for the determination of NICS via square - wave voltammetry ${ }^{(19)}$, cyclic voltammetry at a glassy carbon electrode (20). The purpose of the current work was the description of a simple and sensitive spectrophotometric estimation of NICS. The method based on reduction of nitro group of NICS then reaction of RNICS with NNDMABA in non-aqueous medium (methanol) to form a colored product that has been proved successfully for the estimation of NICS in pharmaceutical and veterinary formulations.

\section{MATERIALS AND METHOD}

\section{Apparatus}

Spectrophotometric measurements were carried out on Shimadzu UV-Visible Spectrophotometer UV160 , using $1-\mathrm{cm}$ quart cells.

\section{Reagents}

All reagents used are of analytical grade and are obtained from Fluka or Aldrich, NICS was supplied from SIGMA companies.

\section{Reagents preparation}

Methanolic solution of PNNDMABA (Fluka) 3\%, weighing $3 \mathrm{~g}$ and dissolved in $100 \mathrm{ml}$ methanol in a volumetric flask. All other reagents were prepared by dissolving the propriety weight in perfect solvent.

\section{Reduction of nitro group in NICS}

A $0.25 \mathrm{~g}$ of pure NICS was dissolved in a $15 \mathrm{ml}$ of a mixture containing ethanol: acetone (1:1) (1), and the volume was completed to $25 \mathrm{ml}$ in volumetric flask with the same mixture. A $5 \mathrm{ml}$ of solution was treated with $0.1 \mathrm{~g}$ of zinc powder and $5 \mathrm{ml}$ of hydrochloric acid $(1 \mathrm{M})$. After standing for 15 minutes in water-bath at $90 \mathrm{C}^{\circ}$, the solution was cooled in icebath, then; the solution was filtered out the insoluble material. The remains were washed with distilled water, and the volume of the filtrate completed up to $100 \mathrm{ml}$ with distilled water in a volumetric flask. The final solution of RNICS in work containing 100 $\mu$ g.ml-1 was prepared by further dilution. 


\section{Recommended procedure}

A volume in the range of 0.1 to $1.7 \mathrm{ml}$ of $100 \mu \mathrm{g} . \mathrm{ml}-$ 1RNICS solution was transferred to $10 \mathrm{ml}$ calibrated flasks. $2 \mathrm{ml}$ of PNNDMABA (3.0\%) was added, and the volume was made up to $10 \mathrm{ml}$ by adding methanol. The yellow Schiff's base was measured at 454 $\mathrm{nm}$ versus a blank solution.

\section{Analysis of NICS in pharmaceutical and veteri-} nary preparations.

Ten tablets (for each formulation individually) were weighed and finely powdered. The powder amount equivalent to $0.25 \mathrm{~g}$ of NICS was taken and the procedure mentioned before is followed (the procedure for reduction of the nitro group). Solutions (100 $\mu \mathrm{g} \cdot \mathrm{ml}^{-1}$ ) of pharmaceutical and veterinary preparations were prepared, and then the suggested procedure was proceeded.

\section{RESULTS AND DISCUSSION}

\section{The principle of reactions}

Reduction of the nitro group in NICS by adding zinc powder and hydrochloric acid (as mention above) to produce RNICS.

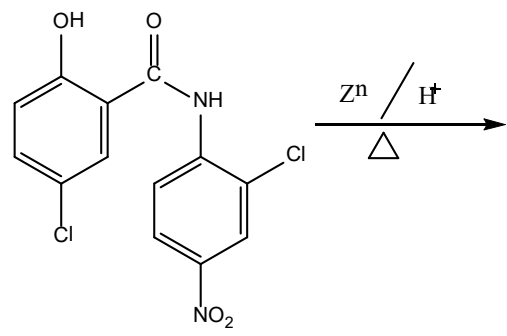<smiles>Nc1ccc(NC(=O)c2cc(Cl)ccc2O)c(Cl)c1</smiles>

The aromatic amine (RNICS) in presence of acid undergoes a condensation reaction in to form a yellow Schiff's base with a maximum absorbance at 454 nm (scheme 2).



Scheme 2. The formation of yellow Schiff's base. 
All parameters affected the A of the yellow Schiff's base were investigated in order to construct the optimum conditions.

Selection of aldehyde.

Table 1 contains the results of using different alde- hydes. The results illustrated in Table 1 indicated that PNNDMABA gives the highest intensity of colored product and good color contrast, so that it selected in the next experiments.

Table 1. The selection of aldehyde



*Absorbance without acid or base $=0.449$ at $\mathrm{pH}=3.00$

Table (3) included the results of using four types of buffer solution with $\mathrm{pH}=3$, there was a decrease in absorption intensity compared to the absence of these solutions; therefore the addition was eliminat- ed in subsequent experiments. The addition of the reaction components, which gives the optimal $\mathrm{pH}$, has been maintained. 
Table 3. The effect of buffer solutions.

\begin{tabular}{llllll}
\hline $\begin{array}{l}\text { Buffer solution } \\
\text { pH 3.0 }\end{array}$ & \multicolumn{2}{l}{ Absorbance /min } & & & \\
\hline Formic acid/KOH & 0 & 10 & 15 & 20 & 30 \\
Tartaric acid/ NaOH & 0.147 & 0.198 & 0.207 & 0.210 & 0.215 \\
KH phathalate/HCl & 0.145 & 0.205 & 0.217 & 0.238 & 0.297 \\
Glycine/HCl & 0.247 & 0.374 & 0.398 & 0.396 & 0.404 \\
Without buffer & 0.430 & 0.445 & 0.446 & 0.445 & 0.446 \\
\hline
\end{tabular}

\section{The effect of PNNDMBA concentration}

To a series of solutions containing 50-150 $\mu \mathrm{g}$. of RNICS, various volumes of PNNDMBA (3.0\%), then addition of methanol in a $100 \mathrm{ml}$ volumetric flasks. The obtained results indicated that the absorbance increase with increasing reagent concentration and reached maximum on adding volume of $2.0 \mathrm{ml}$ of $(3 \%)$ PNNDMABA, which also gives the highest value of determination coefficient (R2). Therefore, the addition of $2 \mathrm{ml}$ reagent was recommended for the subsequent experiments (Table 4).

Table 4. The effect of PNNDMBA concentration.

\begin{tabular}{cccccc}
\hline $\begin{array}{c}\text { Volume of 3\% } \\
\text { PNNDMBA (m) }\end{array}$ & $\mathbf{5 0}$ & \multicolumn{2}{c}{ Absorbance/ $\boldsymbol{\mu g}$ RNICS } & $\mathbf{R}^{\mathbf{2}}$ \\
\hline 0.5 & 0.226 & $\mathbf{7 5}$ & $\mathbf{1 0 0}$ & $\mathbf{1 5 0}$ & 0.98746 \\
1.0 & 0.434 & 0.395 & 0.446 & 0.790 & 0.98966 \\
1.5 & 0.473 & 0.782 & 0.787 & 1.054 & 0.99781 \\
2.0 & 0.506 & 0.739 & 1.021 & 1.289 & 0.99829 \\
2.5 & 0.502 & 0.720 & 1.013 & 1.426 & 0.99771 \\
3.0 & 0.493 & 0.703 & 1.009 & 1.406 & 0.99664 \\
\hline
\end{tabular}

\section{The medium of dilution}

Water, organic solvents and mixtures of solvents in different ratio have been tested for optimum condition. The results illustrated in Table 5.
Table 5 indicated that methanol was the optimum solvent used in dilution according to high intensity of Schiff's base and the good stability.

Table 5. The medium of dilution.

\begin{tabular}{|c|c|c|c|}
\hline Solvent & $\lambda_{\max }(\mathrm{nm})$ & A & $\varepsilon, 1 . \mathrm{mol}^{-1} \cdot \mathrm{cm}^{-1}$ \\
\hline Ethanol & 454 & 0.833 & $\times 10^{4} 2.724$ \\
\hline Methanol & 454 & 1.030 & $\times 10^{4} 3.369$ \\
\hline Formic acid & 454 & 0.955 & $\times 10^{4} 3.123$ \\
\hline Acetone & Turbid & & \\
\hline n-Propanol & 453 & 0.775 & $\times 10^{4} 2.535$ \\
\hline Water & Turbid & & \\
\hline Methanol: Water (1:1) & 455 & 0.709 & $\times 10^{4} 2.319$ \\
\hline Ethanol: Water (1:1) & 456 & 0.639 & $\times 10^{4} 2.090$ \\
\hline
\end{tabular}


The stability of the yellow Schiff's base

The effect of time on the development and stability period of the Schiff's base was investigated under optimum conditions described before. The formation of the yellow Schiff's base being complete after mixing the components of reaction and the abs. of yellow Schiff's base remained constant for at least 2 hours.

\section{The optimum conditions}

The optimum conditions which constructed from the previous experiences were illustrated in table 6 , which were maintained.in subsequent experiments

Table 6. The optimum condition.

\begin{tabular}{ll}
\hline Variable & Optimum \\
\hline Wavelength & $455 \mathrm{~nm}$ \\
Volume of p-NNDMABA & $2 \mathrm{ml}(3.0 \%)$ \\
$\mathrm{pH}$ & 3 \\
Time of measurement & After dilution \\
Medium of reaction & Non-aqueous solvent (methanol) \\
\hline
\end{tabular}

\section{Estimation of absorption maximum}

RNICS was coupling with PNNDMABA in methanolic medium to produce a yellow Schiff's base. The absorption spectra were taken against blank in the range 200-800 nm. Maximum absorption wavelength for RNICS was established to be $454 \mathrm{~nm}$. Under the optimum conditions, the blank showed a negligible abs. at the related lmax (Fig. 1)

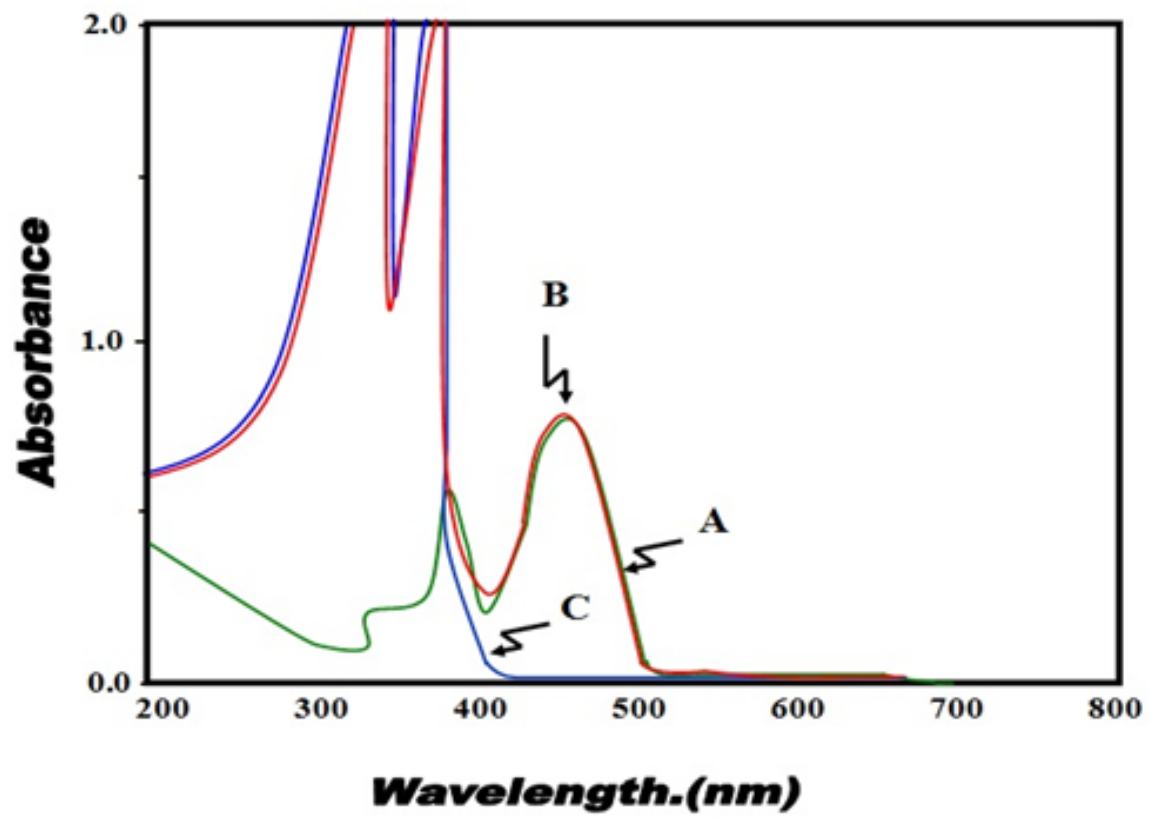

Fig.1. Absorption spectrum of: A-The Schiff's base against blank B- Schiff's base against distilled water. C- Blank against distilled water. 


\section{The Linearity}

Fig 2, showed a good strength line from 10 to170 $\mu \mathrm{g} / 10 \mathrm{ml}(1$ to $17 \mu \mathrm{g} / \mathrm{ml})$.

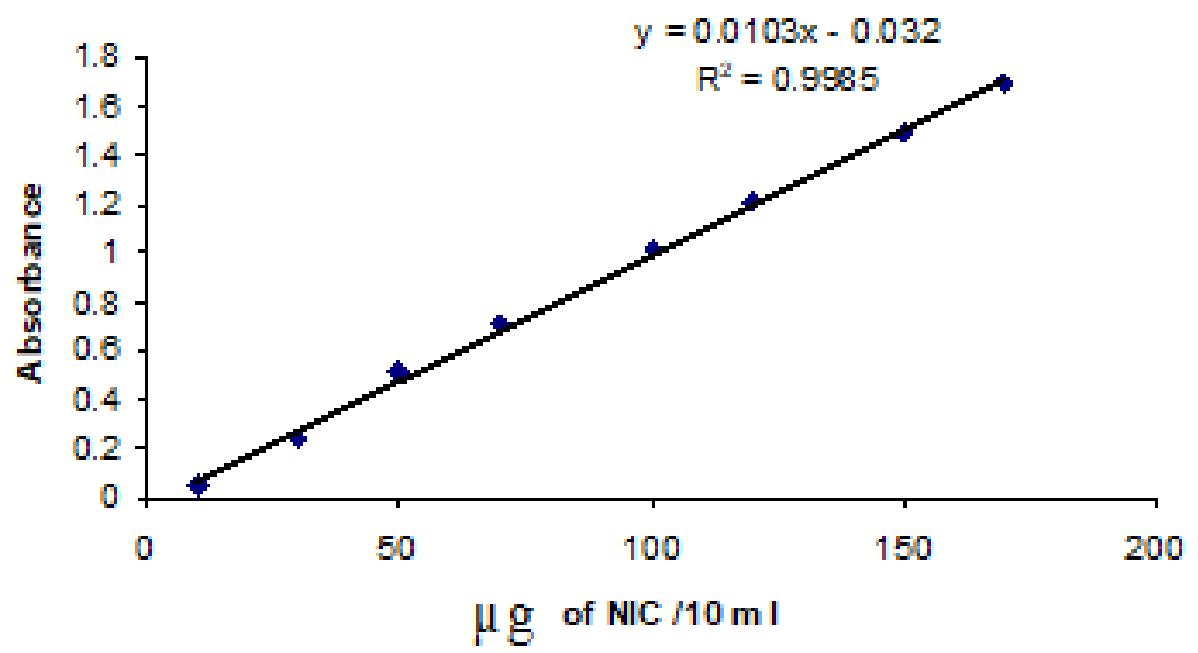

Fig. 2. Calibration graph for NICS determination using the proposed method.

\section{Optical characteristics}

Analytical variation such as the range of Beer's law, molar absorptivity factor and Sandell's sensitivity index are given in Table 7.

Table 7. Some optical characteristics.

\begin{tabular}{|c|c|}
\hline Parameters & Value \\
\hline$\lambda_{\max }(\mathrm{nm})$ & 454 \\
\hline Limits of Beer's law ( $\left.\mu \mathrm{g} \cdot \mathrm{ml}^{-1}\right)$ & $1.0-17.0$ \\
\hline Molar absorptivity factor $\left(1 . \mathrm{mol}^{-1} \mathrm{~cm}^{-} 1\right)$ & $3.369 \times 10^{4}$ \\
\hline Sandell's sensitivity y index $\left(\mu \mathrm{g} \cdot \mathrm{cm}^{-2}\right)$ & 0.0097 \\
\hline Regression equation & $\mathrm{Y}=\mathrm{bX}-\mathrm{C}$ \\
\hline Slope (b) & 0.0103 \\
\hline Intercept (c) & -0.032 \\
\hline Determination coefficient $\left(\mathrm{R}^{2}\right)$ & 0.9984 \\
\hline Relative standard deviation (R.S.D\%) & $0.616 \pm 0.205$ to \pm \\
\hline $\operatorname{LOD}\left(\mu \mathrm{g} \cdot \mathrm{ml}^{-1}\right)$ & 0.00813 \\
\hline LOQ ( $\left.\mu g \cdot \mathrm{ml}^{-1}\right)$ & 0.02711 \\
\hline Stability (hrs.) & 2 \\
\hline Color & Yellow \\
\hline
\end{tabular}

\section{Application part}

in its pharmaceutical (Tablet) and veterinary drugs The method was successfully applied to assay NICS form formulations (Table 8 and 9 respectively) 
Table 8. The results of determination NICS in tablet.

\begin{tabular}{lccc}
\hline Drug & $\begin{array}{c}\boldsymbol{\mu g} \\
\text { RNICS } \\
\text { present }\end{array}$ & $\begin{array}{c}\boldsymbol{\mu g} \\
\text { RNICS } \\
\text { measured }\end{array}$ & $\begin{array}{c}\text { Recovery } \\
(\mathbf{\%})^{*}\end{array}$ \\
\hline \multirow{2}{*}{ Yomesan 500mg /Tablet } & 50 & 49.8 & 99.6 \\
& 100 & 100.3 & 100.3 \\
& 150 & 149.2 & 99.2 \\
\hline
\end{tabular}

*Average of five determinations.

Table 9. The results of determination NICS in veterinary preparations.

\begin{tabular}{lccc}
\hline Veterinary preparations & $\begin{array}{c}\boldsymbol{\mu g} \\
\text { RNICS present }\end{array}$ & $\begin{array}{c}\boldsymbol{\mu g} \\
\text { RNICS measured }\end{array}$ & $\begin{array}{c}\text { Recovery } \\
(\%) *\end{array}$ \\
\hline Niclosamide 1250mg/Tablet & 50 & 49.0 & 98.0 \\
& 100 & 98.8 & 98.8 \\
& 150 & 148.8 & 99.2 \\
Niclosan 250mg/Tablet & 50 & 47.4 & 95.6 \\
& 100 & 97.8 & 97.8 \\
& 150 & 142.9 & 95.3 \\
\hline
\end{tabular}

*Average of five determinations.

The performance of the suggested method was assessed by calculation of t-test compared with the typical method (1) for 95\% confidence rank with eight degrees of freedom. The calculated value was less than the critical value, indicated that there were no significant differences between the present and standard methods for NICS estimation.

\section{CONCLUSION}

Accurate and sensitive spectrophotometric method was described for the estimation of NICS.. The present method has been successfully applied for the estimation of NICS in pharmaceutical and veterinary preparations.

\section{REFERENCES}

1. British Pharmacopeia (2000) CD-Rom, 3rd Edn. System Simulation Ltd., the Stationary Office, London.

2. Wu Y, Yang T, Li X, and Wu J.. Novel derivatives of niclosamid synthesis:Its bioactivity and interaction with Schistosoma Japonicum cercariae. Dyes and Pigm.2011; 88(3): 326-332. https://doi.org/10.1016/j.dyepig.2010.08.002

3. Sheng L,Wei W,Tain X, Jun L. A strategy for emergency treatment of schistosoma Japonicum -infested water. Parasites \& Vectors.2011; 4(1):209-213. https://doi.org/10.1186/17563305-4-209

4. Fomovska A, Wood R, Mui E, Dubey J. Salicylanilide inhibitors of toxoplasma gondii . J. Med. Chem.2012; 55(19):8375- 8391. https://doi.org/10.1021/jm3007596 
5. Sastry C, Aruna M Rama A. Spectrophotometric determination of some antiamoebic and anthelmintic drugs with metol and chromium (VI).Talanta ,1988; 35 (1): 23-26.

https://doi.org/10.1016/0039-9140(88)80006-7

6. Othman NA, and Sultan SA. Spectrophotometric determination of niclosamide by prior reduction and subsequent diazotization-coupling with 2,6-dihydroxybenzoic acid - Application to tablets, Raf. J. Sci .2014;25(1) :40-52.

7. Othman NA, Sultan SA. Indirect spectrophotometric determination of niclosamide in pharmaceutical preparation. J.Edu. and Scie./Pure Scie.2018;27(3):40-52.

https://doi.org/10.33899/edusj.2018.159307

8. Abdel Fattah, S. Spectrophotometric determination of niclosamide using p-benzoquinone. Spectrosc. Lett., 1970;30(5):795-804. https://doi.org/10.1080/00387019708001628

9. Daabees H. Selective differential spectrophotometric methods for determination of niclosamide and drotaverine hydrochloride. Anal. Lett.2000; 33 (4): 639-656.

https://doi.org/10.1080/00032710008543080

10. Onur F, Tekin N. Spectrophotometric determination of niclosamide and thiabendazole in tablets. Anal . Lett.1994; 27 (12):2291-2301. https://doi.org/10.1080/00032719408005983

11. Lopatin B, Lopatina N,Bekhli A. Spectrophotometric determination of fenasal (niclosamide) in tablets. Farmatsiya (Moscow).1989; 38(3): 7576.

12. Cirkovic MI, Kartalovic BR, Novakov NI ,Pelic MI,DjordjevicVL, Radosavljevic, VL, Aleksic NE. Distribution of niclosamide residues in meat and internal organs of common carp, Procedia Food Scie..2015;5:54 - 56. https://doi.org/10.1016/j.profoo.2015.09.014

13. Kartalović BR, Pucarević MI., Zoran MA., Stanković MA.,Novakov NI, Pelić MI, Ćirković MI. Determination of niclosamide and its metabolites in liver and muscles of common carp (Cyprinus carpio) fingerlings, Acta Scie. Veter.2017;45:1-6. https://doi.org/10.22456/1679-9216.80635
14.Paghadar C, Vadia N. Development and validation of stability indicating RP-HPLC and HPTLC for determination of Niclosamide in bulk and in synthetic mixture, Arabian J. of Chem..2015:1-12. https://doi.org/10.1016/j.arabjc.2014.11.064

15. Cholifah S, Kartinasari W, Indrayanto G. Simultaneous HPLC determination of levamisole hydrochloride and anhydrous niclosamide in veterinary powders and its validation. J. Liq.Chromatogr. Rel. Technol.2008; 31(2):281-291.

https://doi.org/10.1080/10826070701739132

16. Caldow M, Sharman M, Kelly M, Day J, ;Hird $\mathrm{S}$, Tarbin J. Multi- residue determination of phenolic and salicylanilide anthelmintics and related compounds in bovine kidney by liquid chromatography - tandem mass spectrometry. J. Chromatogr.2009;1216(46): 8200-8205.

https://doi.org/10.1016/j.chroma.2009.04.008

17.Yongtao L,Fuhua W,Xiaohui A,Zhenyue W,Qiuhong Y,Jing D.Dong Residue depletion and risk assessment of niclosamide in three species of freshwater fish, Food Additives \& Contaminants: Part A. 2018; 35(8): 1497-1507.

https://doi.org/10.1080/19440049.2018.1488184

18. John S, Geoffrey B.Estimation of residues of the molluscicide, niclosamide, in bananas by gas-liquid chroymatograph of the heptafluorobutyryle derivative of the substituted aniline moiety.Pest Sci.1980; 10(6): 531-539.

https://doi.org/10.1002/ps.2780100614

19. Alemu H, Khoabane $\mathrm{N}$ and Tseki P. Electrochemical oxidation of Niclosamide at aglassy carbon electrode and its determination by voltammetry.Bull.Chem.Soc.Ethiopia.2003; 17(1): 95-106.

https://doi.org/10.4314/bcse.v17i1.61740

20.Abreu,F, Goulart,M,and Oliveira, A. Detection of the damage caused to DNA by niclosamide using an electrochemical DNA-biosensor. Biosen. and Bioelectro.2002; 17:913-919. https://doi.org/10.1016/S0956-5663(02)00082-9 